\title{
Aplicación móvil para Aprender Lengua de Señas Mexicana
}

\section{Mobile Application for Learning Mexican Sign Language}

\author{
ROJAS-CHÁVEZ, Keyla Arisbeth†*, QUINI-VILLEGAS, Ricardo y GONZÁLEZ-RAMÍREZ, \\ Claudia Teresa
}

Instituto Tecnológico de Zitácuaro / Tecnológico Nacional de México, Av. Tecnológico No. 186 Manzanillos, C.P. 61534 H. Zitácuaro.Michoacán

ID $1^{\text {er }}$ Autor: Keyla Arisbeth, Rojas-Chávez / ORC ID: 0000-0002-0217-9644

ID $1^{\mathrm{er}}$ Coautor: Ricardo, Quini-Villegas / ORC ID: 0000-00002-3914-9860

ID $2^{\text {do }}$ Coautor: Claudia Teresa, González-Ramírez / ORC ID: 0000-0002-4106-4583, Researcher ID Thomson: G-63132019, Open ID: 10218204610851314995

DOI: $10.35429 / J I T C .2019 .8 .3 .8 .17$

Recibido 06 de Abril, 2019; Aceptado 25 de Junio, 2019

\section{Resumen}

En este artículo se presenta el modelo de una aplicación móvil, como una herramienta de apoyo de aprendizaje, para niños y adultos que presenten discapacidad auditiva o no, aprendiendo de la Lengua de Señas Mexicana. Esto se pretende lograr por medio de imágenes animadas, un juego y un traductor que deletrea las palabras por medio del abecedario dactilológico. Apoyados por la Unidad de Servicios de Apoyo a la Educación Regular (USAER) misma que está incorporada a la SEP, ubicada en Morelia, Michoacán. Así mismo como la Asociación Civil "Mis manos hablan para ayudar", la cual se ubica en Zitácuaro, Michoacán. Facilitando el aprendizaje con esta aplicación móvil que está diseñada ad hoc a la región oriente de Michoacán, sustentado por intérpretes de la Lengua de Señas. El uso de la tecnología móvil permite que más personas puedan tener acceso a este tipo de herramientas agilizando y facilitando el aprendizaje y la enseñanza. Con esto se pretende que el pensamiento humano evolucione para que las personas que presentan esta condición puedan después aportar sus ideas y conocimientos en un futuro.

Discapacidad, Móvil, Aprendizaje

\begin{abstract}
This article presents the model of a mobile application, as a learning support tool, for children and adults who have a hearing disability or not, learning the Mexican Sign Language. This is to be achieved by means of animated images, a game and a translator who spells the words by means of the dactylographic alphabet. Supported by the Regular Education Support Services Unit (USAER), which is incorporated into the SEP, located in Morelia, Michoacán. Also like the Civil Association "My hands speak to help", which is located in Zitácuaro, Michoacán. Facilitating learning with this mobile application that is designed ad hoc to the eastern region of Michoacán, supported by sign language interpreters. The use of mobile technology allows more people to have access to this type of tools, facilitating learning and teaching. This is intended to human thinking to evolve so that people who have this condition can then contribute their ideas and knowledge in the future.
\end{abstract}

Disability, Mobile, Learning

Citación: ROJAS-CHÁVEZ, Keyla Arisbeth, QUINI-VILLEGAS, Ricardo y GONZÁLEZ-RAMÍREZ, Claudia Teresa. Aplicación móvil para Aprender Lengua de Señas Mexicana. Revista de Tecnologías de la Información y Comunicaciones. 2019. 3-8:8-17

\footnotetext{
* Correspondencia del Autor (Correo electrónico: keyla_5395@ hotmail.com)

$\dagger$ Investigador contribuyendo como primer autor.
} 


\section{Introducción}

La dificultad de las personas con discapacidad auditiva para comunicarse con los demás, limita su desarrollo educativo, profesional y humano, por consecuencia, se ponen en riesgo sus oportunidades de inclusión y ante esta necesidad, las personas sordas han desarrollado su propia forma de comunicación.

Por tal motivo, se propone generar una aplicación multimedia enfocada a la enseñanza de la Lengua de Señas Mexicana (LSM), para niños y adultos, implementada en la plataforma Android Studio; para esto se procede hacer un caso de estudio en la dependencia USAER, la cual da cuenta de los estudiantes de educación especial que tienen discapacidad auditiva. Por ello, se busca fomentar la creación de material pedagógico que apoye la inclusión de poblaciones en el contexto de la diversidad como lo es la población sorda, y esto se logra mediante el uso de la tecnología.

Además, con esta aplicación se propone que el pensamiento humano vaya evolucionando y cambiando el concepto de vida de todo ser vivo, pues los sordos también requieren de una mayor consideración ya que personas con gran interés tienen la intención de ayudarles, buscando la forma y la manera de que sean integrados a la sociedad, con el propósito de ser considerados seres racionales y con derecho a la educación y al respeto como personas; pues solo tienen la dificultad de no tener un lenguaje para expresar sus ideas

\section{Antecedentes}

La Lengua de Señas Mexicanas (LSM), es la lengua que utilizan las personas sordas en México. Y como toda lengua, posee su propia sintaxis, gramática y léxico. Su composición es de signos visuales con estructura lingüística propia, con la cual se identifican y expresan las personas sordas en México. Una Aplicación móvil (App) se define en el Diccionario de Informática y Tecnología como "aquella desarrollada especialmente para ser ejecutada en dispositivos móviles como un teléfono celular, tabletas y similares estas aplicaciones tienen características especiales para poder funcionar en estos dispositivos móviles que, por lo general, tienen menos capacidad de procesamiento y almace- namiento que computadoras de escritorio o notebooks". (ALEGSA, 2017)
Por su parte Entrepreneur en su artículo 7 características de la generación $\mathrm{Z}$, menciona que esta generación real- mente pone en alto el término multipantalla controlando cinco pantallas a la vez. La generación $\mathrm{Z}$ se comunica con imágenes y crea contenidos. Se enfocan en el futuro, es una generación realista. La generación $\mathrm{Z}$ trabaja para obtener éxito personal (De Barba, 2016).

El artículo "Las Apps más usadas por los mexicanos en 2016" (Universia, 2016), menciona que casi la mitad de los mexicanos poseen Smartphones y los usan la mayor parte del tiempo en aplicaciones, en un estudio realizado por ComScore obtuvo como resultado que las Apps más usadas por los mexicanos son en orden de preferencia: WhatsApp, Google Play, YouTube, Google Search, Facebook Messenger, Facebook, Google Calendar y Gmail.

Las aplicaciones móviles son una tendencia para las generaciones digitales pues estas se han popularizado porque funcionan como herramientas para realizar tareas de todo tipo y así facilitar las actividades de quienes las usan.

\section{Justificación}

Según datos estadísticos de la OMS el 15\% de la población mundial presenta alguna discapacidad, de los cuales el 5\% son sordos, esto es; una tercera parte de esos pobladores del mundo presentan esta condición. La sordera en sí no representa una barrera para el aprendizaje y la participación, sobre todo cuando se ha perdido la audición después de haber adquirido la capacidad de hablar leer y escribir, pero cuando la pérdida es temprana y no se trata de manera adecuada a la persona con sordera, esta tiene limitaciones en su desempeño social.

Los padres son quienes enseñan a hablar a sus hijos y toda vez que detectan que sus vástagos no escuchan debieran aprender el nuevo código para comunicarse, pero, difícilmente ocurre, la mayoría de los alumnos que llegan a la educación especial han perdido sus primeros años para aprender a comunicarse usando señas de manera convencional. La tecnología corre a gran velocidad y ha venido a revolucionar la vida, hoy el mundo no es como hace 50 años, se ha avanzado en materia de salud, sistemas de comunicación, transporte, etc. 
Lemas como "Hagamos tecnología creativa para ser útil a México", son ejemplos de la preocupación de la educación por hacer uso de la tecnología para favorecer los procesos de enseñanza-aprendizaje. Actualmente, es más común ver a niños usando tabletas, celulares, juegos electrónicos que leyendo un libro, para los adultos es más común buscar y encontrar información en la web que haciendo consultas bibliográficas, es por ello; que se pretende enseñar a una persona en esta realidad. Preferiblemente a través de los medios tecnológicos debido a que la mayoría de la población tiene acceso a ellos.

\section{Objetivos}

\section{General}

Desarrollar una aplicación móvil en la plataforma Android Studio, para el aprendizaje de la Lengua de Señas Mexicana (LSM).

\section{Específicos}

Desarrollar un menú en donde aparezcan las funciones de la aplicación móvil.

Realizar un módulo que contenga el vocabulario básico de la LSM, interpretando mediante imágenes animadas el modo o movimiento correcto de realizar una seña de cada palabra.

Hacer que el vocabulario básico esté por categorías para el fácil aprendizaje de los sordos y oyentes.

Generar un juego de opción múltiple que retroalimente lo aprendido mediante imágenes animadas al azar.

Efectuar un traductor de la LSM para el deletreo de palabras.

\section{Pregunta de investigación}

¿Con una herramienta tecnológica como lo es un app ayuda al aprendizaje de Lengua de Señas Mexicana?

\section{Metodología}

Análisis del funcionamiento del sistema

El entorno de desarrollo integrado (IDE) oficial para el desarrollo de aplicaciones es Android Studio y se basa en IntelliJ IDEA. Además del potente editor de códigos y las herramientas para desarrolladores de IntelliJ, ya que ofrece aún más funciones que aumentan la productividad durante la compilación de apps para Android, como son las siguientes:

- Un emulador rápido con varias funciones.

Un entorno unificado en el que puedes realizar desarrollos para todos los dispositivos Android.

- Instant Run para aplicar cambios mientras la app se ejecuta sin la necesidad de compilar un nuevo APK.

- Integración de plantillas de código y GitHub para ayudarte a compilar funciones comunes de las apps e importar ejemplos de código.

- Gran cantidad de herramientas y frameworks de prueba.

- Herramientas Lint para detectar problemas de rendimiento, usabilidad, compatibilidad de versión, etc.

Compatibilidad con $\mathrm{C}++\mathrm{y}$ NDK.

- $\quad$ Soporte incorporado para Google Cloud Platform, lo que facilita la integración de Google Cloud Messaging y App Engine.

\section{Estructura del proyecto}

Cada proyecto en Android Studio contiene uno o más módulos con archivos de código fuente y archivos de recursos. Entre los tipos de módulos se incluyen los siguientes:

Módulos de apps para Android.

Módulos de bibliotecas.

Módulos de Google App Engine.

\section{Metodología de producto}

Con la metodología Scrum el cliente se entusiasma y se compromete con el proyecto dado que lo ve crecer iteración a iteración. Asimismo, le permite en cualquier momento realinear la aplicación con los objetivos establecidos en la dependencia, ya que puede introducir cambios funcionales o de prioridad 


\section{Procedimiento de SCRUM}

En Scrum un proyecto se ejecuta en ciclos temporales cortos y de duración fija (iteraciones que normalmente son de 2 semanas, aunque en algunos equipos son de 3 y hasta 4 semanas límite máximo). Cada iteración tiene que proporcionar un resultado completo, un incremento de producto final que sea susceptible de ser entregado con el mínimo esfuerzo al cliente cuando lo solicite. en el inicio de cada nueva iteración sin ningún problema.

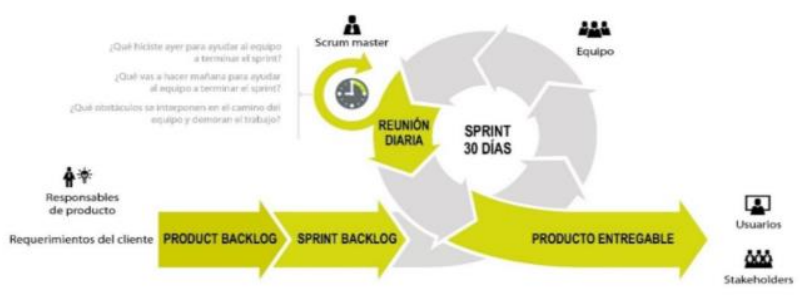

Figura 1 Diagrama de metodología SCRUM

\section{Identificación de requerimientos para la creación de los módulos}

Para brindar ayuda a las personas con alguna discapacidad auditiva se plantearon distintos módulos que mejoran la calidad de vida de las personas sordas, aportando medios por los cuales puedan comunicarse.

Por tanto, a continuación, se nombran las herramientas existentes que ayudara al desarrollo de los módulos.

\section{- Abecedario dactilológico mexicano \\ - Ideogramas \\ - $\quad$ Manos con voz \\ - $\quad$ Método perceptivo discriminativo \\ - Discriminación visual}

\section{Implicados}

- $\quad 10$ niños con discapacidad auditiva, sus edades que oscilan entre los 6 y 14 años de edad.

3 docentes relacionados al área de educación especial con énfasis en nisordos y/o con problemas de aprendizaje.

- $\quad$ USAER y CAMP ZITÁCUARO

\section{Diseño de las operaciones del módulo}

Para la aplicación móvil se demanda la creación e implementación de tres módulos unidos por un menú principal, los módulos fueron los siguientes de acuerdo a la figura 2 :

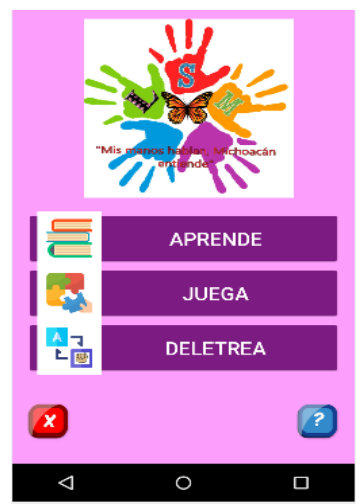

Figura 2 Módulos de la aplicación

Módulo "Aprende". Se espera que este tenga el vocabulario básico de la LSM, conformada por 16 categorías en donde en cada una de ellas se tenga las imágenes animadas realizando la seña, y que vaya acorde al campo semántico. Además de colocar como extra la enseñanza de la lecto-escritura por medio de los títulos y palabras resaltadas en color rojo, así como el texto de la descripción de las señas.

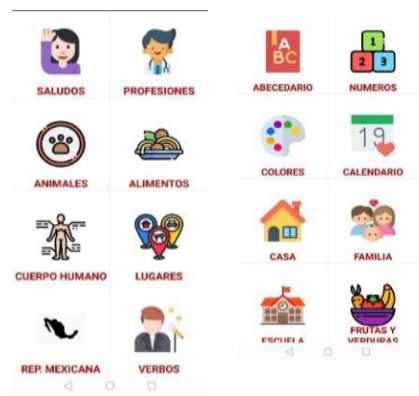

Figura 3 Categorías del módulo "Aprende"

La mayoría de las categorías se sacaron del libro manos con voz, además de las señas y su descripción. Se ideó que al momento de que se presione en cualquiera de las categorías muestre una pantalla con un actor haciendo la seña de una palabra. Para ello se contaron con dos actores para la realización de las señas.

\section{Juega}

El botón Juega para que la persona con sordera pueda asociarlo, se le asignó una imagen de un rompecabezas; dando a entender que se trata de un juego interactivo y divertido. 


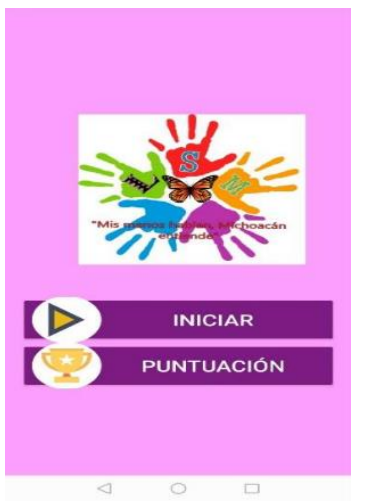

Figura 4 Menú Juega

El juego favorece el desarrollo intelectual. A la vez que el niño juega, crea cosas, inventa situaciones y busca soluciones a diferentes problemas que se le plantean a través de los juegos. El juego implica creación, imaginación, exploración, fantasía, el niño aprende a prestar atención en lo que está haciendo, a memorizar, razonar, etc. La actividad mental en el juego es continua, a través del juego, su pensamiento se desarrolla. Así que, por medio de las imágenes ya realizadas se crea un juego de opción múltiple con la finalidad de que el niño aprenda de manera lúdica.

Se recomienda que primero se vean todas las imágenes animadas del módulo aprende, para que puedan memorizar la seña y así poder ganar el juego.

- Se obtiene una puntuación y 3 corazones los cuales representan las oportunidades o vidas.

- Cada acierto otorga 10 puntos en la puntuación.

Por una que no sepa, se le quita un corazón y a parte pierde 10 puntos.

- $\quad$ Si pierde las 3 vidas, al final se le otorga una oportunidad.

El que acierte sin perder ninguna vida, tendrá el beneficio de estar en primer lugar en el TOP PUNTAJES.

El TOP PUNTAJES, aparece en el historial de las veces que juegas, esto para que ayude al usuario a superarse en cada reto y a parte aprender de manera más rápida y divertida.

Módulo "Juega". Por medio del aprendizaje que se obtuvo en el módulo anterior, se solicita de la creación de un juego dinámico de opción múltiple, en donde aparezca una imagen animada al azar para poner a prueba la retención de aprendizaje, así como de generar entretenimiento e interacción.

\section{Deletrea}

El botón Deletrea es para que la persona con sordera pueda asociarlo, por lo tanto, se le asignó una imagen de un traductor; dando a entender que se pueden traducir las palabras de español a señas y de señas a español.

En este módulo se pretende que el usuario aprenda señas y español al mismo tiempo, y que también sea una manera de traducir mediante el abecedario dactilológico lo que quiere decir, sería la mejor forma de interactuar con los demás.

El traductor es dirigido a la comunidad oyente y sorda con el fin de que inicie un proceso de aprendizaje autónomo de la lengua de señas mexicana, y así poder realizar la inclusión de las personas sordas en todos los proceso sociales y culturales de nuestra sociedad.

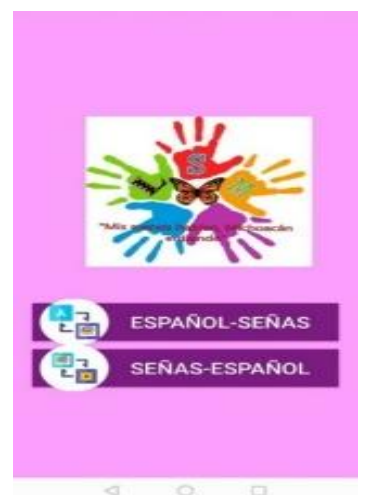

Figura 5 Menú deletrea

\section{Español-Señas}

La primera opción de este menú comparte la misma imagen que la del menú principal, se crea un teclado en español para poder convertir las palabras en señas de manera dactilógica.

Debajo del teclado también se agregaron botones los cuales tendrán la siguiente funcionalidad:

\footnotetext{
- $\quad$ Botón espacio: crea un espacio entre las palabras.

- Botón limpiar: borra todas las palabras que se escribieron.

- Botón de flecha regresiva: con este, podrás borras letra por letra.

Botón de traducir: este te dirige a la pantalla en donde se traduce el español a señas.
} 


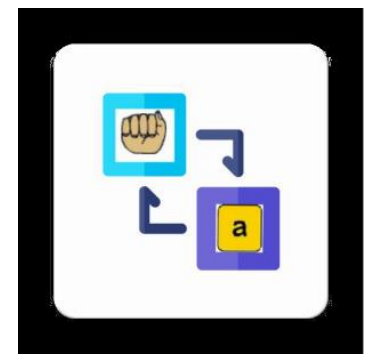

Figura 6 Español-Señas

HOLA

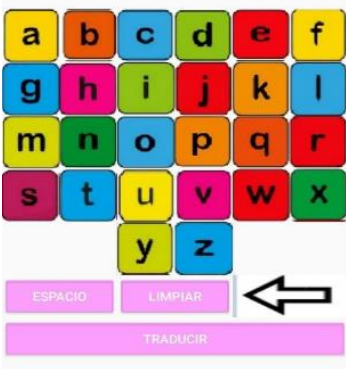

Figura 7 Traducido-español-señas

\section{Señas-Español}

La segunda opción de este menú se le asignó la siguiente imagen:

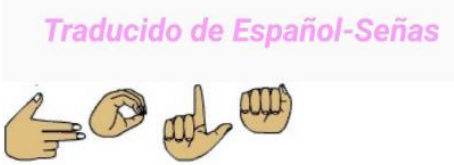

Figura 8 Deletrea-botón-señas-español

Se crea un teclado en señas para poder convertir las palabras en español. Debajo del teclado también se agregaron botones los cuales tienen signos y tienen la siguiente funcionalidad:

Botón “O | O": crea un espacio entre las palabras, el signo significa la separación de las letras.

- Botón "////"”: borra todas las palabras que se escribieron, el signo significa como un efecto borrador.

- Botón de flecha regresiva: con este, podrás borras letra por letra. 56

Botón --- $\rightarrow+1$ : este te dirige a la pantalla en donde se traduce el español a señas, el signo significa que solo se debe presionar una sola vez.

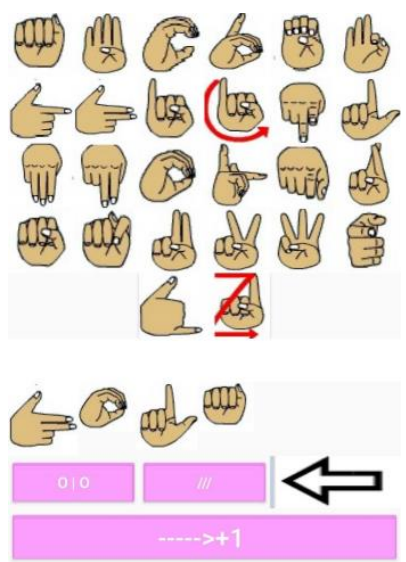

Figura 9 Señas-Español

Como ejemplo, se escribe de igual manera la palabra "HOLA" mediante el abecedario dactilológico, destacando que este apartado es para las personas con sordera, o si ya tienen un conocimiento de la lengua de señas, como se observa en la figura 10.

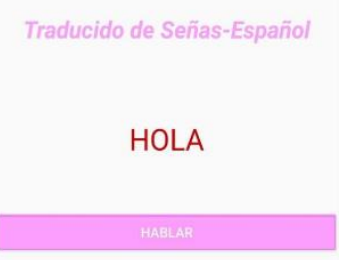

Figura 10 Traducido-señas-español

Destacando que no solo se puede poner una sola palabra, tiene un límite para 10 palabras seguidas o una oración corta. Una vez que se traduce lo escrito en señas, al momento de presionar el botón "HABLAR" éste va a decir lo que está escrito en la pantalla. Esta es una forma de que la aplicación puede hablar por la persona con sordera; además de que aprenda el idioma español.

\section{Resultados}

Para validar los criterios de usabilidad y aceptación se establecen los siguientes parámetros:

\section{- $\quad$ Rendimiento \\ - $\quad$ Facilidad de aprendizaje \\ - $\quad$ Flexibilidad}




\section{Rendimiento}

Para establecer el rendimiento de la aplicación se ejecutan pruebas sobre el código mediante la función interna: Android Profile. Una vez, realizado los anteriores pasos, la aplicación se ejecutará, esto con la intención de que, al momento de presionar las funciones de la misma, veamos como este trabaja de manera óptima y lo podemos deducir por lo siguiente:

A continuación, se logra observar cómo calcula el rendimiento del Splash y del menú principal.

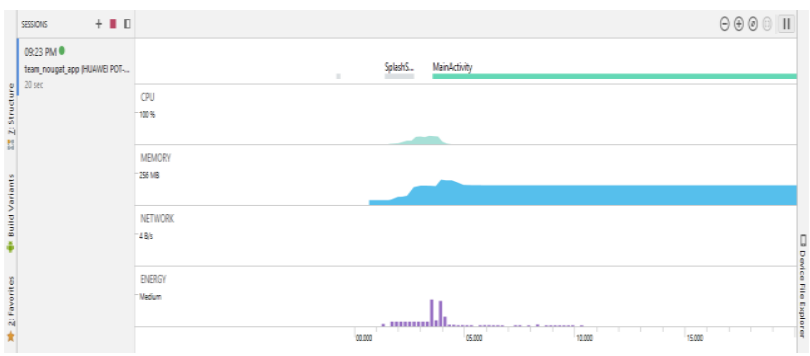

Figura 11 Optimización de Splash y Menú principalproliferó

También se midió el rendimiento de los módulos: Aprende, Juega y Deletrea.

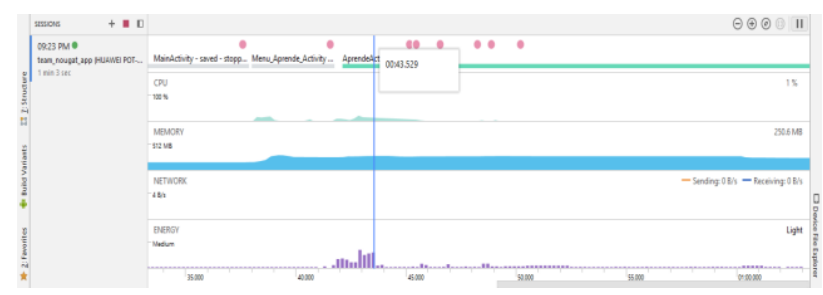

Figura 12 Optimización de Menú Aprende y Aprendeprofiler

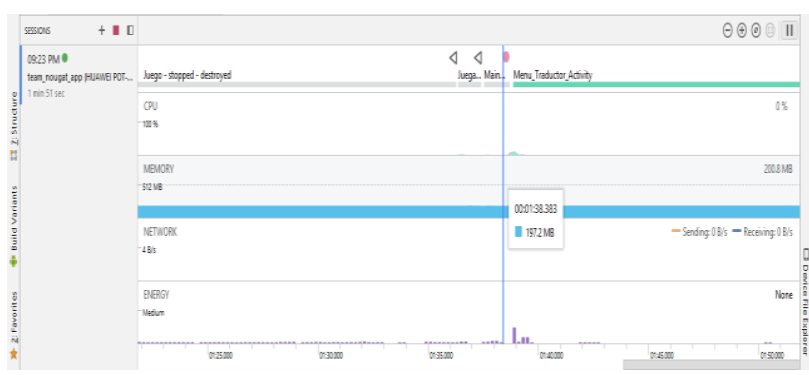

Figura 13 Optimización de Menú Deletrea y Deletreaprofiler

El tiempo de carga y velocidad que muestra, se debe a que la aplicación tiene pocos componentes pesados y en su desarrollo se utilizaron imágenes en formato .gif, .jpg y .png, esto fue un factor para que el rendimiento de la aplicación fuera óptimo.

\section{Resultados cualitativos}

Optimización: la aplicación brinda una excelente navegabilidad, ya que al momento de escribir o de ver alguna categoría éste lo realiza de manera rápida sin trabarse o demorarse en cargar alguna de las imágenes.

Accesibilidad: el acceso inmediato de tener la aplicación en el celular y poder disfrutar de las funciones que ofrece.

Adaptabilidad: Permite que, en cualquier momento, en un futuro sea posible hacerle modificaciones para enriquecer aún más la aplicación.

Facilidad de uso: la aplicación es completamente intuitiva, puesto que la pantalla que se muestra al usuario se desarrolló de manera que todos puedan manejarla, ya que la intención es que el usuario no tenga dificultad para hacer uso de ella.

\section{Resultados cuantitativos}

¿TE PARECE FÁCIL DE USAR?

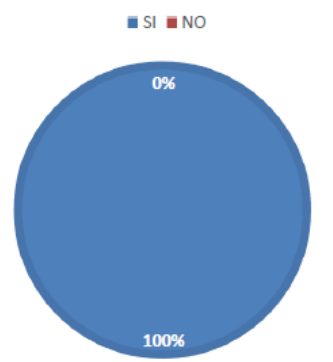

Gráfica 1 Facilidad de uso

¿TE GUSTÓ EL JUEGO?

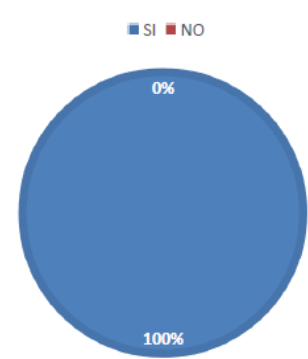

Gráfica 2 Factibilidad de la aplicación 


\section{¿LOS MÓDULOS QUE SE ENCUENTRAN EN LA APP, APOYAN EL DESARROLLO PEDAGÓGICO DEL NIÑO?}

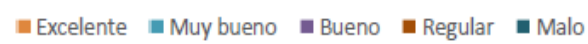

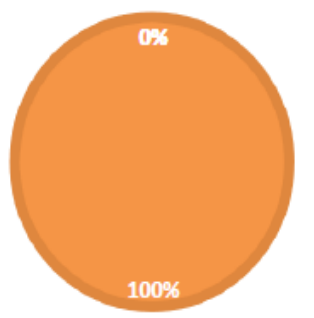

Gráfica 3 Fácil de usar

¿TE PARECIÓ ÚTIL TRADUCIR O DELETREAR?

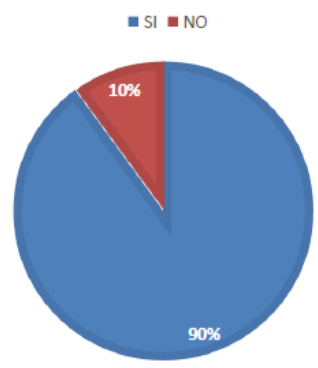

Gráfica 4 Apoyo en la enseñanza

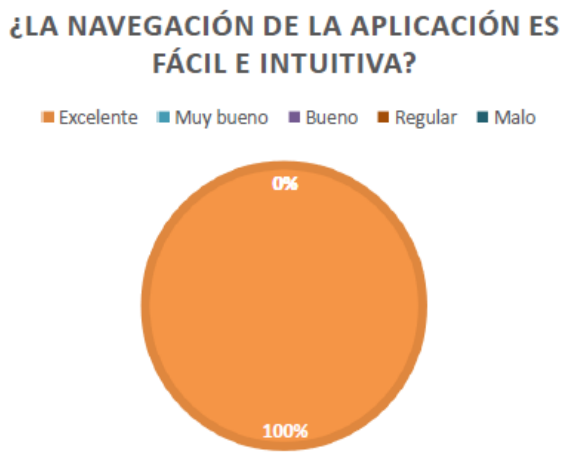

Gráfica 5 Facilidad de navegación

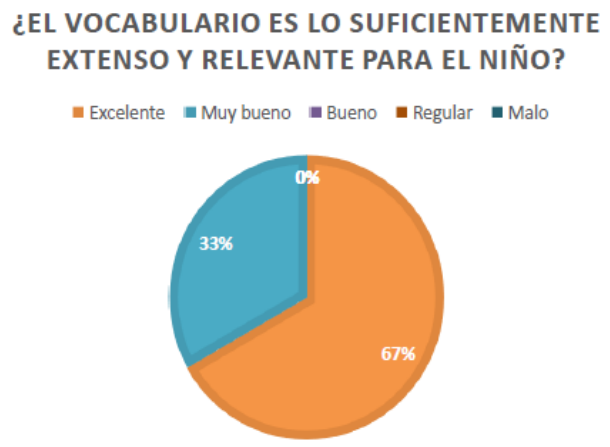

Gráfica 6 Vocabulario suficiente

\section{CALIFIQUE LA APP DE MANERA GENERAL, TENIENDO EN CUENTA SU PRINCIPAL OBJETIVO, LA ENSEÑANZA DE LA LSM}

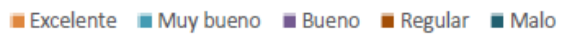

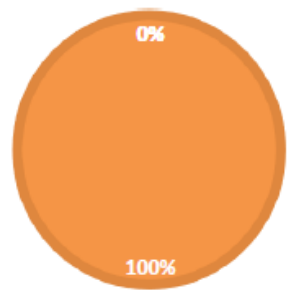

Gráfica 7 Apoyo en la enseñanza de LSM

\section{Discusión}

El desarrollo de las interfaces proporcionó una interacción amigable y fácil de ejecutar, de manera que todas las personas, tanto sordas como oyentes, puedan hacer uso de la aplicación sin ninguna dificultad.

El uso de los colores presentes en la aplicación, así como las imágenes asociadas a la misma, establecen una interfaz amigable, fundamentada mediante el método perceptivo discriminativo.

Al desarrollar la aplicación para dispositivos móviles se tiene la ventaja de contar con las funcionalidades táctiles de este, permitiendo así tener una navegabilidad basada en el movimiento de las manos, lo cual estimula las facultades motoras del niño y perceptible para las personas adultas.

\section{Conclusiones}

Al desarrollar la aplicación para dispositivos móviles se tiene la ventaja de contar con las funcionalidades táctiles de este, permitiendo así tener una navegabilidad basada en el movimiento de las manos, lo cual estimula las facultades motoras del niño.

La naturaleza móvil de la aplicación propicia espacios alternativos distintos al aula de clase para la enseñanza de la lengua de señas mexicanas, permitiendo tener una alta disponibilidad de los contenidos generados para el aprendizaje. 


\section{Agradecimiento}

En el marco de política educativa nacional, la Dirección de Educación Especial que proyecta su ser y quehacer institucional en la mejora de la calidad educativa a través del fortalecimiento del Modelo de Atención de los Servicios de Educación Especial CAM y Unidades de Servicios de Apoyo a la Educación RegularUSAER, con la intención de brindar un marco referencial y operativo acorde con los retos que enfrentan las escuelas ante las demandas de una sociedad en transformación que implica una formación integral y significativa para todos, gracias por dejar de ser parte de este gran proyecto y al Instituto Tecnológico de Zitácuaro por facilitar las interacciones y brindar el apoyo incondicional para el desarrollo del proyecto.

\section{Referencias}

ALEGSA. (2017). Definición de aplicación móvil (app). Recuperado de http://www.alegsa.com.ar/Dic/aplica-

cion_movil.php

bbc.com (2014). ¿Cuántos sordos existen en el mundo? Recuperado de: https://www.bbc.com/mundo/noticias/2014/08/ 140808_salud_cinco_cosas_que_no_sabe_sord era_lv [Accesado: 05 febrero 2019].

developer.android.com (2018). Estructura del sistema Android Studio Recuperado de: https://developer.android.com/studio[Accesado: 19 abril 2019].

De Barba, G. (2010). 7 características de la generación $Z$. Recuperado de https://www.entrepreneur.com/arti- cle/268023 [Accesado: 12 octubre 2019]

Fuentes López, G., \& Méndez Ruiz, R. C. (2019). Turismo incluyente para sordos en el jardín botánico Dr. Faustino Miranda y el zoológico Miguel Álvarez del Toro (Doctoral dissertation, Facultad de HumanidadesLicenciatura en Lenguas con enfoque TurísticoUNICACH).

García, I. C., \& Mesa, M. L. C. (2019). Las generaciones digitales y las aplicaciones móviles como refuerzo educativo. Revista Metropolitana de Ciencias Aplicadas, 2(1), 25-31
Gómez, E. G., Yahuarcani, I. O., Lagos, K. D. J., \& Llaja, L. A. S. (2019). Warma: aplicativo móvil para el aprendizaje de matemáticas y lenguaje en instituciones educativas de las comunidades quechua hablantes en Ayacucho. PURIQ, 1(01), 79-97.

geocities.ws (2014). Qué son los ideogramas y ejemplos Recuperado de: http: //www.geocities.ws/hramosara/ideogramas.html [Accesado: 21 mayo 2019].

issuu.com (2015). ¿Qué significa USAER y cuáles son sus funciones? Recuperado de: https://issuu.com/jesuspl/docs/_qu__significa _usaer_y_c_mo_surg[Accesado: 03 marzo 2019].

inclusionchapultepec.blogspot.com (2016). Método perceptivo discriminativo y ejemplos Recuperado de: http://inclusionchapultepec.blogspot.com/2016/ 01/metodo-de-aprendizaje-perceptivo.html

Manos con voz, María Esther Serafín de Fleischmann y Raúl González Pérez. (2011). Libre Acceso A.C. Consejo Nacional para Prevenir la Discriminación. México 2011. p. 1.

Mora Ramírez, J. L. (2019). Diseño de una aplicación WEB para la accesibilidad en el aprendizaje de nuevas tecnologías en personas con discapacidades físico-motoras y visuales de la asociación Pues al cielo Cantón Balzar

Loza, R., \& Eduardo, C. (2019). Impacto de la aplicación Reader como herramienta de apoyo en la lectoescritura de las personas con discapacidad auditiva de la Asociación Central de Sordos El Alto. Fides et Ratio-Revista de Difusión cultural y científica de la Universidad La Salle en Bolivia, 17(17), 239-258.

periodicoeldespertar.com (2017). Asociación Civil, "Mis manos hablan para ayudar" Recuperado de: https://www.periodicoeldespertar.com/editorial/ personaje-de-la-semana/elizabeth-rodriguezarroyo/[Accesado: 19 abril 2019].

pinterest.com.mx (2018). Abecedario dactilológico Recuperado de: https://www.pinterest.com.mx/pin/2977302253 49909584/?lp=true[Accesado: 21 mayo 2019]. 
portaldeeducacion.com.mx (2018). ¿Cuándo surgió la USAER? Recuperado de: https://portaldeeducacion.com.mx/educacionespecial-usaer/index.htm[Accesado: 03 marzo 2019].

wikiversity.org (2018). Discapacidad auditiva Recuperado de: https://es.wikiversity.org/wiki/Discapacidad_au ditiva[Accesado: 20 mayo 2019]. 